Article

\title{
Numerical Study of Entropy Generation in a Flowing Nanofluid Used in Micro- and Minichannels
}

\author{
Mohammadreza Hassan ${ }^{1}$, Rad Sadri ${ }^{1, *}$, Goodarz Ahmadi $^{2}$, Mahidzal B. Dahari ${ }^{3}$, \\ Salim N. Kazi ${ }^{1}$, Mohammad R. Safaei ${ }^{1}$ and Emad Sadeghinezhad ${ }^{1}$
}

1 Department of Mechanical Engineering, Faculty of Engineering, University of Malaya, 50603, Kuala Lumpur, Malaysia; E-Mails: mohamadreza@siswa.um.edu.my (M.H.); salimnewaz@um.edu.my (S.N.K.); cfd_safaei@yahoo.com (M.R.S.); esn802001@yahoo.com (E.S.) Department of Mechanical and Aeronautical Engineering, Clarkson University, Potsdam, NY 13699, USA; E-Mail: gahmadi@clarkson.edu (G.A.)

3 Department of Engineering Design and Manufacture, Faculty of Engineering Building, University of Malaya, 50603 Kuala Lumpur, Malaysia; E-Mail: mahidzal@um.edu.my (M.B.D.)

* Author to whom correspondence should be addressed; E-Mail: rod.sadri@gmail.com; Tel.: +60-14-2276015.

Received: 13 November 2012; in revised form: 4 December 2012; / Accepted: 7 December 2012 / Published: 7 January 2013

\begin{abstract}
This article mainly concerns theoretical research on entropy generation influences due to heat transfer and flow in nanofluid suspensions. A conventional nanofluid of alumina-water $\left(\mathrm{Al}_{2} \mathrm{O}_{3}-\mathrm{H}_{2} \mathrm{O}\right)$ was considered as the fluid model. Due to the sensitivity of entropy to duct diameter, mini- and microchannels with diameters of $3 \mathrm{~mm}$ and $0.05 \mathrm{~mm}$ were considered, and a laminar flow regime was assumed. The conductivity and viscosity of two different nanofluid models were examined with the help of theoretical and experimentally determined parameter values. It was shown that order of the magnitude analysis can be used for estimating entropy generation characteristics of nanofluids in mini- and microchannels. It was found that using highly viscous alumina-water nanofluid under laminar flow regime in microchannels was not desirable. Thus, there is a need for the development of low viscosity alumina-water $\left(\mathrm{Al}_{2} \mathrm{O}_{3}-\mathrm{H}_{2} \mathrm{O}\right)$ nanofluids for use in microchannels under laminar flow condition. On the other hand, $\mathrm{Al}_{2} \mathrm{O}_{3}-\mathrm{H}_{2} \mathrm{O}$ nanofluid was a superior coolant under laminar flow regime in minichannels. The presented results also indicate that flow friction and thermal irreversibility are, respectively, more significant at lower and higher tube diameters.
\end{abstract}


Keywords: nanofluid; entropy generation; microchannel; laminar flow; minichannel

\section{Nomenclature}

\begin{tabular}{|cccc|}
\hline$\Phi$ & volume fraction & $\mathrm{C}_{\mathrm{p}}$ & Specific heat J/KG. $\mathrm{k}$ \\
$f$ & friction factor & $\mathrm{K}$ & thermal conductivity \\
$\mathrm{D}$ & diameter of tube, $\mathrm{m}$ & $\mathrm{N}$ & shape constant \\
$\mathrm{Nu}$ & Nusselt Number & $\mathrm{P}$ & density \\
$R e$ & Reynolds Number & & mass flow rate \\
$\mathrm{Be}$ & Bejan Number & $\mu$ & Viscosity \\
$g e n$ & entropy generation per unit length, & Subscript & \\
& W/m.k & & base fluid \\
$q^{\prime \prime}$ & heat flux per unit length, W/m & $\mathrm{BF}$ & nanofluid \\
$\mathrm{C}_{\mu}$ & viscosity coefficient & $\mathrm{NF}$ & nanoparticles \\
$\mathrm{C}_{\mathrm{k}}$ & thermal conductivity coefficient & $\mathrm{P}$ & \\
\hline
\end{tabular}

\section{Introduction}

In the past few decades, along with the continuous growth of industries and developments in nanotechnology, a need has arisen for more effective methods of cooling and for enhanced heat transfer characteristics. The heat transfer process is central to many engineering applications (i.e., car radiators, refrigerators, power generation plants, industrial heat exchangers, etc.). The performance of micro-electromechanical systems (MEMS) in heat transfer devices and engines is improved with the increasing ability of a fluid medium to transfer large amounts of heat through a small temperature difference, which enhances the efficiency of converting energy in these devices [1]. This circumstance has led to the appearance of a new group of coolants using nanofluids. The heat transfer performance of liquids including suspended solid nanopowders was investigated by Masuda et al. in 1993 [2]. Nonetheless, Choi was the first to introduce the notion of nanofluids in 1995 [3,4]. Nanofluids are a new generation of heat conducting fluids consisting of a base fluid with suspended nano-sized particles in the range of 1 100 nm. Because solid particles have higher thermal conductivity compared to the conventional base fluid, it is expected that the addition of solid nanoparticles would increase the effective thermal conductivity of the nanofluids [5,6]. For instance, the thermal conductivity of $\mathrm{Cu}$ (copper) is 700 and 3,000 times the heat conductivity of water and engine oil, respectively [7].

The heat transfer enhancement of nanofluids is due to an increase of the base fluid thermal conductivity due to the presence of nanoparticles. As expected, the addition of nanoparticles also increases the viscosity of the base fluid (for example, see [8]). Thus, evaluating the advantages of using nanofluids should not be considered purely on the basis of thermal conductivity [9]. Recent experimental evidence testifies that nanofluids exhibit viscosity and heat conductivity behaviors which are different from their theoretically calculated values. In particular, the experimentally observed viscosity values are more than the predicted theoretical values for particle suspensions. 
Numerous studies have revealed the advantages of nanofluids over base fluids regarding higher thermal conductivity. A theoretical analysis of nanofluid flow was reported by Prasher et al. [10]. They compared the pressure drop of base fluids and nanofluids when the heat transfer coefficient for both fluids was equal. They indicated that replacing base fluids with nanofluids is advantageous only when the increment in conductivity is four times more than the increment in viscosity; that is, $4 \mathrm{C}_{\mathrm{k}}>\mathrm{C}_{\mu}$, where $C_{k}$ is the conductivity coefficient and $C_{\mu}$ is the viscosity coefficient [10]. Similarly, Garg et al. [11] observed that if the diameter of the pipe through which the nanofluids flow remain sun changed, the use of a nanofluidis not helpful; however, if the pipe diameter increases proportionally to the thermal conductivity of the nanofluid, replacing the base fluid with a nanofluid, with $\mathrm{C}_{\mu}<5 \mathrm{C}_{\mathrm{k}}$ as a coolant, becomes advantageous.

Typical evaluation techniques aim to achieve maximum heat transfer and are commonly used to assess heat exchanger performance. However, the increase of heat transfer does not essentially imply a decline in irreversibility [12,13]. Assessing irreversibility by measuring entropy generations an effective way of estimating whether a selected system is achieving an effectual goal or not [14]. Heat transfer through a finite temperature difference, chemical reaction, mixing, friction, and so on, is a key factor leading to the occurrence of irreversibility in a system, which causes what is known as entropy generation within the system [14-16]. According to the equations derived by Bejan $[17,18]$ the entropy generation consists of two main parts: (a) losses due to frictional factors and (b) thermal irreversibility.

The goal of this study was to analyze the entropy generation in heat conducting nanofluids and to assess the benefits and disadvantages of nanofluids compared to the base fluids. While the analysis could be applied to any nanofluid, an alumina-water nanofluid is used as the model due to the accessibility of its physical properties. To estimate the exergetic characteristics of nanofluids, the influences of tube diameter, fluid properties and the particle concentration on the rate of entropy generation are investigated. Based on the simulation results, recommendations on the advantageous use of nanofluids for convective thermal transport are made.

\section{Methodology}

The fundamental equations governing entropy generation in a heat conducting duct of diameter D was given by Bejan $[17,18]$.Accordingly, the rate of entropy generation is given as:

$$
\begin{gathered}
\text { gen }=\left(\begin{array}{c}
\text { gen } \\
)_{\text {fluid friction }}+(\text { gen }
\end{array}\right)_{\text {heat transfer }} \\
\text { gen }=\frac{8^{3}}{\mathrm{~T}^{2} \pi^{2}} \frac{f\left((\mathrm{Re})_{\mathrm{D}}\right)}{\mathrm{D}^{5}}+\frac{\mathrm{D}^{2} \pi \mathrm{q}^{\prime 2}}{\mathrm{~T}^{2} \mathrm{kNu}\left((\mathrm{Re})_{\mathrm{D}}, \mathrm{Pr}\right)}
\end{gathered}
$$

where $\operatorname{Re}=4 / \pi \mu \mathrm{D}$ is the Reynolds number and $f=64 / \mathrm{Re}$.

It is seen that Equation (1) consists of two parts. The first part contains the entropy generation due to frictional behavior where some parameters such as , $\rho$, Re and $\mathrm{D}^{2}$ play a significant role. The second part is entropy generation due to heat transfer. For a fully developed laminar flow regime in a channel, the Nusselt number is independent of axial location, Prandtl number, and Reynolds number and is given as $\mathrm{Nu}=4.365$. Then the Bejan equation is simplified to: 


$$
\text { gen }=\frac{128^{2} \mu}{T \rho^{2} \pi D^{4}}+\frac{D^{2} \pi q^{\prime 2}}{4.365 \mathrm{KT}^{2}}
$$

Defining $Z_{1}=\frac{128^{2}}{D^{4} \pi}$ and $Z_{2}=\frac{\mathrm{D}^{2} \pi \mathrm{q}^{\prime 2}}{4.365}$, Equation (2) may be restated as:

$$
\text { gen }=\frac{\mathrm{Z}_{1} \mu}{\mathrm{T} \rho^{2}}+\frac{\mathrm{Z}_{2}}{\mathrm{kT}^{2}}
$$

The ratio of entropy generation in the nanofluid to that in the base fluid is given as:

$$
\frac{\text { genNF }}{\text { genBF }}=\left(\frac{K_{B F}}{K_{N F}}\right)\left(\frac{T_{B F}}{T_{N F}}\right)^{2}\left(\frac{\rho_{B F}}{\rho_{N F}}\right)^{2}\left(\frac{Z_{2 N F} \rho^{2}{ }_{N F}+Z_{1 N F} \mu_{N F} T_{N F} K_{N F}}{Z_{2 B F} \rho^{2}{ }_{B F}+Z_{1 B F} \mu_{B F} T_{B F} K_{B F}}\right)
$$

This fraction compares the entropy generation rate in the nanofluid and base fluid. It is obvious that for higher efficiency, less irreversibility and less entropy generation must occur. Therefore, the entropy generation rate in the nanofluid must be less than that in the base fluid; hence, gen,NF/ gen,BF 1 [9].

\subsection{Thermal Properties of Nanofluids}

The properties such as specific heat, density, viscosity, and thermal conductivity as used in Equation (4) should be known. According to many studies on the thermal conductivity of nanofluids, it plays a significant role in the heat transfer of nanofluids; and it has been shown that this parameter has a higher value than that obtained from the Hamilton-Cross theory [19]. Effective thermal conductivity according to Hamilton-Cross is given as:

$$
K_{e f f}=K_{f}\left[K_{p}+(n-1) K_{B F}-(n-1) \phi\left(\mathrm{K}_{\mathrm{BF}}-\mathrm{K}_{\mathrm{p}}\right) /\left[K_{P}+(n-1) K_{B F}+\left(K_{B F}-K_{p}\right) \phi\right]\right.
$$

In this formula different values are obtained for varying shapes. For instance, at high thermal conductivity for spherical particles, Equation (5) reduces to [20]:

$$
\mathrm{K}_{\mathrm{eff}}=\mathrm{k}_{\mathrm{f}}(1+3 \phi)
$$

Nanofluid thermal conductivity and viscosity can be obtained via Equations (7) and (8):

$$
\begin{aligned}
& K_{N F}=K_{B F}\left(1+\mathrm{C}_{\mathrm{k}} \phi\right) \\
& \mu_{N F}=\mu_{B F}\left(1+\mathrm{C}_{\mu} \phi\right)
\end{aligned}
$$

where $C_{k}$ is the conductivity coefficient and $C_{\mu}$ is the viscosity coefficient. Using the data for alumina-water nanofluid from the literature [21-25], the variation of conductivity ratio with solid volume fraction is plotted in Figure 1. It is seen that the majority of the data were located near a straight line that corresponds to $\mathrm{C}_{\mathrm{k}}=4$. Therefore, the experimental value for alumina-water nanofluid thermal conductivity is given by Equation (7) with $\mathrm{C}_{\mathrm{k}}=4$. 
Figure 1. Variation of conductivity ratio with volume fraction based on the data of [21-25].

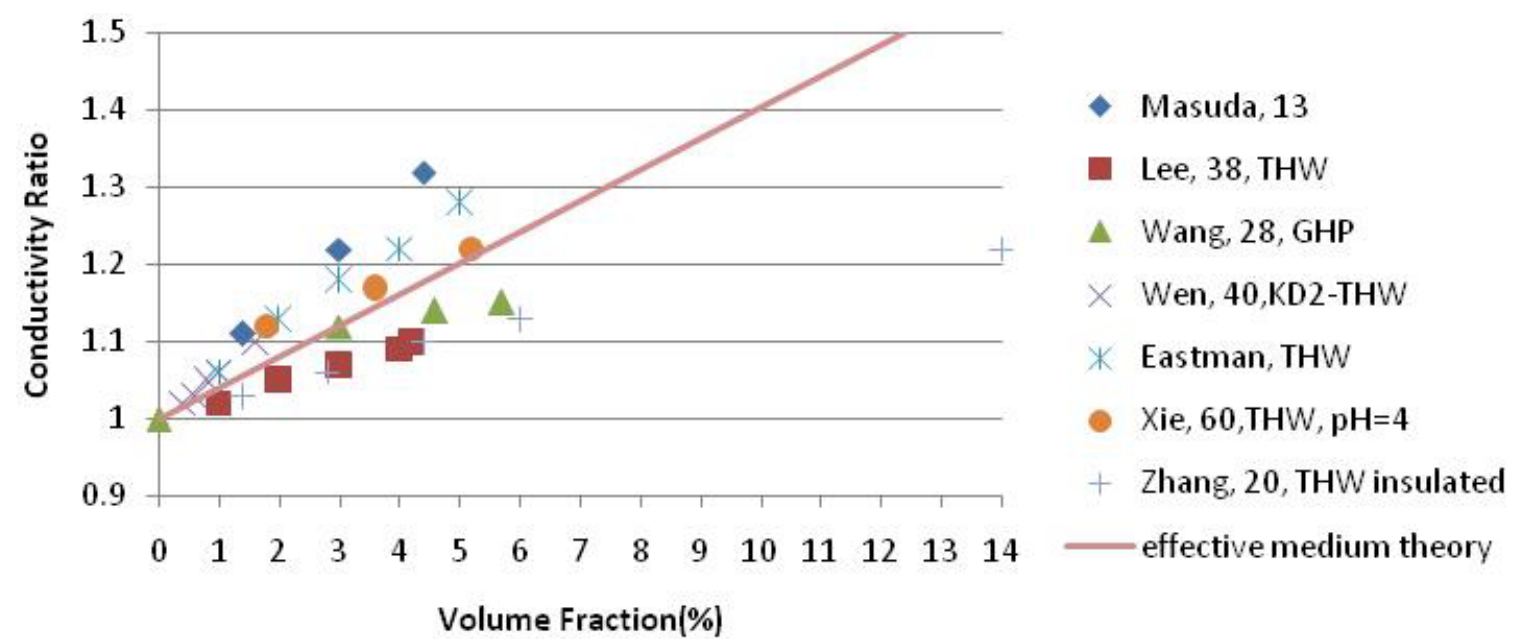

The corresponding data for viscosity of alumina-water nanofluid is plotted in Figure 2. Again a linear fit with $\mathrm{C}_{\mu}=10$ is observed.

Figure 2. Variation of viscosity ratio with volume fraction based on the data of [26-28].

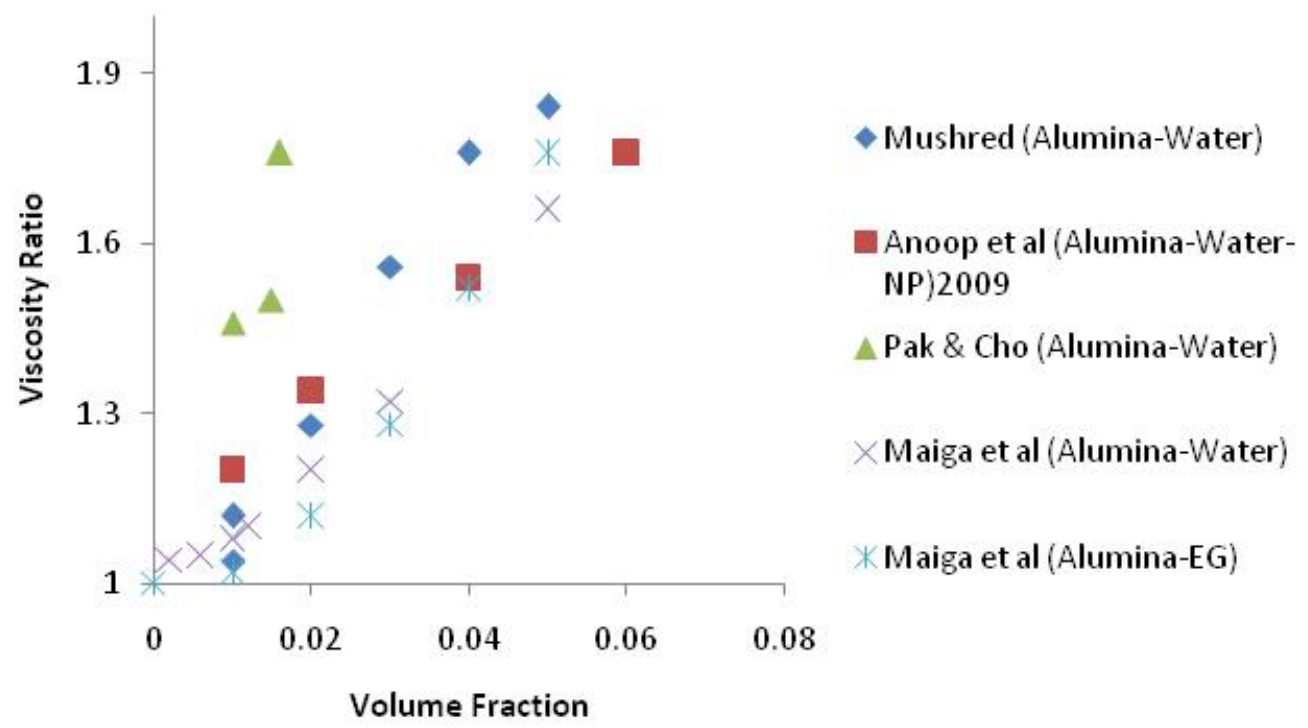

Heat transfer in nanofluids is assessed according to two methods when considering $\mathrm{C}_{\mathrm{k}}$ and $\mathrm{C} \mu$, where one is calculated from the Hamilton-Cross and Einstein equations for the highly dilute suspensions and the other is based on the experimental data $\left(C_{\mu}=10\right.$ and $\left.C_{k}=4\right)$. It is acceptable for the values of $\mathrm{C} \mu$ and $\mathrm{C}_{\mathrm{k}}$ to be between the set two limits.

According to Bergman[29], the trend of density and specific heat of nanofluids is assumed to be similar to that of other mixtures. It has been demonstrated that specific heat evaluated on mass fraction basis is more accurate than that based on volume fraction. That is :

$$
C_{p_{N F}}=\frac{\left(C_{p f} \rho_{f}(1-\phi)+\rho_{p} \phi C_{P_{p}}\right)}{\rho_{f}(1-\phi)+\rho_{p} \phi}
$$


Also, nanofluid total density is given as:

$$
\rho_{\mathrm{NF}}=\rho_{\mathrm{f}}(1-\phi)+\rho_{\mathrm{p}} \phi
$$

It is assumed that some particle parameters affect the entropy generation ratio, but Equation (4) presents an entropy generation ratio with approximated parameter values. By applying approximation, the entropy generation equation becomes simplified. This simple entropy generation ratio form is called predicted value. In the present study, the parameters remain constant at a temperature rise of about $5^{\circ} \mathrm{C}$. This paper investigates heat transfer by applying approximation to the Bejan equation under laminar condition in micro- and mini channels.

\subsection{Microchannels}

By considering Equation (4) and the definition of a microchannel $(0.05 \mathrm{~mm})$ for evaluating the entropy generation ratio, using the values of parameters: $\left(T \propto 10^{\wedge} 2, \mathrm{~K} \propto 1, \propto 10^{\wedge}(-4), \mathrm{q}^{\prime \prime} \propto 10^{\wedge} 2\right.$, $\left.\mu \times 10^{\wedge}(-3), D \propto 10^{\wedge}(-4), \rho^{\propto} 10^{\wedge} 3\right)$, it follows that $Z_{1} \mu \mathrm{KT} \times 10^{9}, Z_{2} \rho 2 \times 10^{6}$, and $Z_{2} \rho^{2}$ are negligible compared to $\mathrm{Z}_{1} \mu \mathrm{KT}$. Therefore:

$$
\frac{\text { genNF }}{\text { genBF }}=\left(\frac{T_{B F}}{T_{N F}}\right)\left(\frac{\mu_{N F}}{\mu_{B F}}\right)\left(\frac{\rho^{2}{ }_{B F}}{\rho^{2}{ }_{N F}}\right)
$$

since $\mathrm{T}_{\mathrm{NF}} \cong \mathrm{T}_{\mathrm{BF}}$.

Hence, after simplification:

$$
\frac{\text { genNF }}{\text { genBF }}=\left(\frac{\mu_{\mathrm{NF}}}{\mu_{\mathrm{BF}}}\right)\left(\frac{\rho^{2}{ }_{\mathrm{BF}}}{\rho^{2}{ }_{\mathrm{NF}}}\right) \approx \frac{1+10 \phi}{\left(1+\left(\frac{\rho_{P}}{\rho_{B F}}-1\right) \phi\right)}
$$

where Equations (8) and (10) are used. Since the density ratio $\rho_{P} / \rho_{B F}$ is always less than 1 , the ratio given by Equation (12) is always more than unity. Therefore, the use of nanofluids in microchannels under laminar flow regime is not recommended.

\subsection{Minichannels}

Again, by applying Equation (4) to the laminar condition for a minichannel of $3 \mathrm{~mm}$ diameter, (T $\propto$ $\left.10^{2}, \mathrm{~K} \propto 1, \propto 10^{(-3)}, \mathrm{D} \propto 10^{(-3)}, \rho \propto 10^{3}, \mu \propto 10^{(-3)}, \mathrm{q}^{\prime \prime} \propto 10^{4}\right)$, we find $\mathrm{Z}_{2} \rho^{2} \propto 10^{8}$ and $\mathrm{Z}_{1} \mu \mathrm{KT} \propto 10^{7}$.It is seen that the orders of terms $Z_{1} \mu \mathrm{KT}$ and $Z_{2} \rho^{2}$ are comparable for laminar flows in a minichannel. Thus, all parameters affect the entropy generation ratio in this case, and the result depends on the operating conditions. It is then possible to assess the effectiveness of a nanofluid for different applications. In particular, the equation for heat transfer of nanofluids in a minichannel needs to be included in the analysis. Depending on the physical properties of the nanofluids and the flow conditions, the use of nanofluids in minichannels may or may not be advantageous. The parameters for calculating entropy generation are presented in Table 1. 
Table 1.The parameters for calculating Entropy Generation.

\begin{tabular}{cc}
\hline \multicolumn{2}{c}{ All the input data for calculation } \\
\hline Data & Values \\
Tin & $300 \mathrm{~K}$ \\
$\Delta \mathrm{T}=$ (Tout-Tin) & $5 \mathrm{~K}$ \\
Length of channel & $1 \mathrm{~m}$ \\
Base fluid (water) density & $1,000 \mathrm{~kg} / \mathrm{m}^{3}$ \\
Base fluid conductivity & $0.6 \mathrm{~W} / \mathrm{mK}^{2}$ \\
Base fluid viscosity & $0.001 \mathrm{~N} \mathrm{~s} / \mathrm{m}^{2}$ \\
Base fluid Cp & $4,180 \mathrm{~kJ} / \mathrm{kg} \mathrm{K}$ \\
Particle (alumina) density & $3,900 \mathrm{~kg} / \mathrm{m}^{3}$ \\
Particle conductivity & $40 \mathrm{~W} / \mathrm{m} \mathrm{K}$ \\
Particle Cp & $880 \mathrm{~kJ} / \mathrm{kg} \mathrm{K}$ \\
Laminar flows & $64 / \mathrm{Re}$ \\
(Friction factor) $f$ & $2,500\left(\mathrm{w} / \mathrm{m}^{2}\right)$ \\
(Heat flux) q" & 1,500 \\
(Reynolds) Re & $48 / 11$ \\
(Nusselt) Nu &
\end{tabular}

All calculation results for different volume fractions are presented in Tables 2 and 3.

Table 2. Laminar flow regime, fully developed.

\begin{tabular}{cccccc}
\hline \multicolumn{5}{c}{ The calculation of entropy generation in microchannel } \\
\hline \multicolumn{5}{c}{ Base Fluid } & \multicolumn{5}{c}{ Nanofluid } \\
Volume Fraction & 0 & 0.02 & 0.06 & 0.1 & 0.14 \\
Śgen, thermal (kJ/kgK) & $2.083 \mathrm{E}^{-7}$ & $1.929 \mathrm{E}^{-7}$ & $1.679 \mathrm{E}^{-7}$ & $1.488 \mathrm{E}^{-7}$ & $1.3354 \mathrm{E}^{-7}$ \\
Śgen, frictional (kJ/kgK) & 0.0754 & 0.116384 & 0.2241 & 0.36246 & 0.46401 \\
Total (kJ/kgK) & 0.0754 & 0.116385 & 0.2241 & 0.36246 & 0.46401 \\
Be (Bejan number) & & $3.76 \mathrm{E}^{-7}$ & $2.7 \mathrm{E}^{-7}$ & $2.7 \mathrm{E}^{-7}$ & $1.92 \mathrm{E}^{-7}$ \\
\hline
\end{tabular}

Table 3. Laminar flow regime, fully developed.

\begin{tabular}{cccccc}
\hline \multicolumn{5}{c}{ The calculations of entropy generation in minichannels } \\
\hline \multicolumn{5}{c}{ Base Fluid } & \multicolumn{5}{c}{ Nanofluid } \\
Volume Fraction & 0 & 0.02 & 0.06 & 0.1 & 0.14 \\
$\dot{\mathrm{S}}_{\text {gen }}$, thermal $(\mathrm{kJ} / \mathrm{kgK})$ & $7.4994 \mathrm{E}^{-4}$ & $6.944 \mathrm{E}^{-4}$ & $6.048 \mathrm{E}^{-4}$ & $5.357 \mathrm{E}^{-4}$ & $4.801 \mathrm{E}^{-4}$ \\
$\dot{\mathrm{S}}_{\mathrm{gen}}$, frictional $(\mathrm{kJ} / \mathrm{kgK})$ & $2.0942 \mathrm{E}^{-5}$ & $3.233 \mathrm{E}^{-5}$ & $6.224 \mathrm{E}^{-5}$ & $1.007 \mathrm{E}^{-4}$ & $1.464 \mathrm{E}^{-4}$ \\
total $(\mathrm{kJ} / \mathrm{kgK})$ & $7.7088 \mathrm{E}^{-4}$ & $7.267 \mathrm{E}^{-4}$ & $6.67 \mathrm{E}^{-4}$ & $6.364 \mathrm{E}^{-4}$ & $6.272 \mathrm{E}^{-4}$ \\
Be (Bejan number) & & 1.256 & 1.397 & 1.594 & 1.873 \\
\hline
\end{tabular}

Figure 3 shows the variation of ratio of entropy generate rate of nanofluids to that of the base fluid in a microchannel as a function of solid volume fraction. It is seen that the entropy generation ratio increases with an increase in the solid volume fraction. As noted before, in microchannels, the increase 
in the density cannot compensate for increased viscosity, and the entropy generation rate is higher than unity. Therefore, the use of a nanofluid under this condition is not recommended.

Figure 3. Entropy generation rate ratio in microchannels.

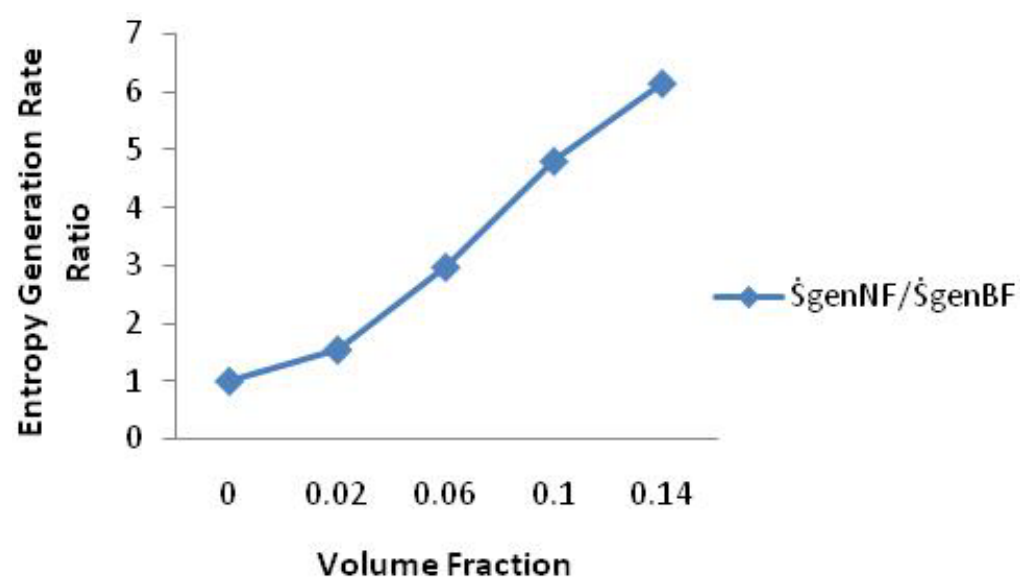

Figure 4 shows the variation of the ratio of entropy generation rate of nanofluids to that of the base fluid in a minichannel as a function of solid volume fraction. It is seen that genNF/ genBF decreases with an increase in volume fraction.

Figure 4. Entropy generation rate ratio in minichannels.

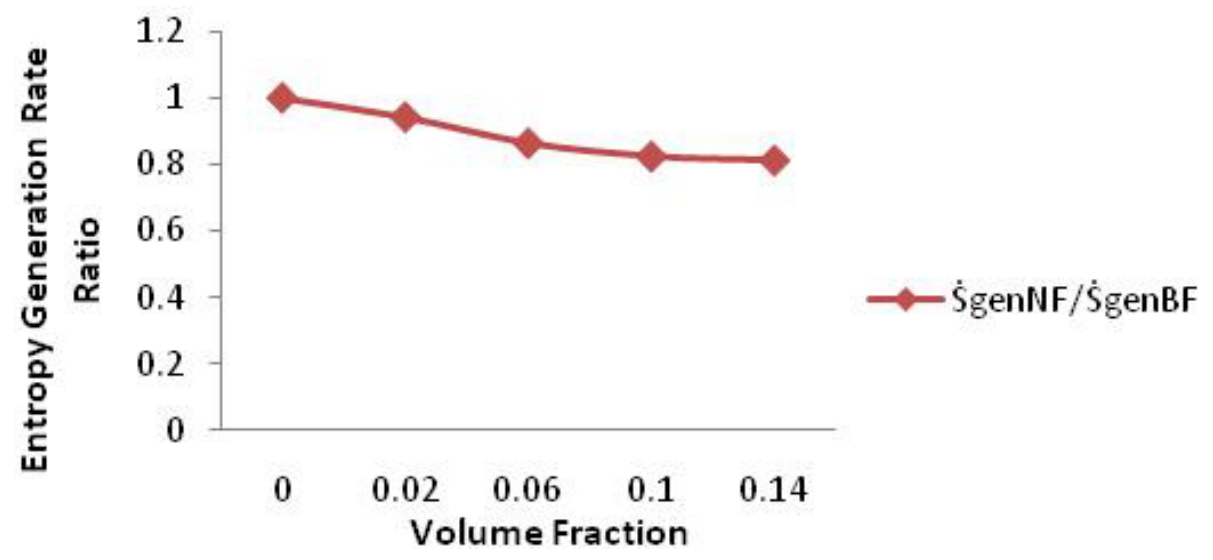

Based on Equations (8), (10) and (12), both $C \mu$ and $\rho_{N F}$ increase when the volume fraction increases. In this type of minichannel, the influence of the $\rho_{N F}$ increment on the decrement of the entropy generation ratio is more significant than the entropy generation ratio increment due to the increase of $\mu_{\mathrm{NF}}$ for any volume fraction. Therefore, in this minichannel the ratio of entropy generation for laminar flow is always lower than unity, and using nanofluids in the minichannel is advantageous.

Figure 5 compares the variation of entropy generation from thermal and frictional irreversibility in microchannels for laminar flow regime. It is observed that the thermal irreversibility declines with the increase of volume fraction, while the frictional irreversibility increases. The increase in frictional entropy generation, however, is much larger than the decrease in the thermal entropy production. The contribution of thermal entropy generation is negligibly small in this case. Therefore, the total entropy production increases. 
Figure 5. Entropy generation in microchannels.

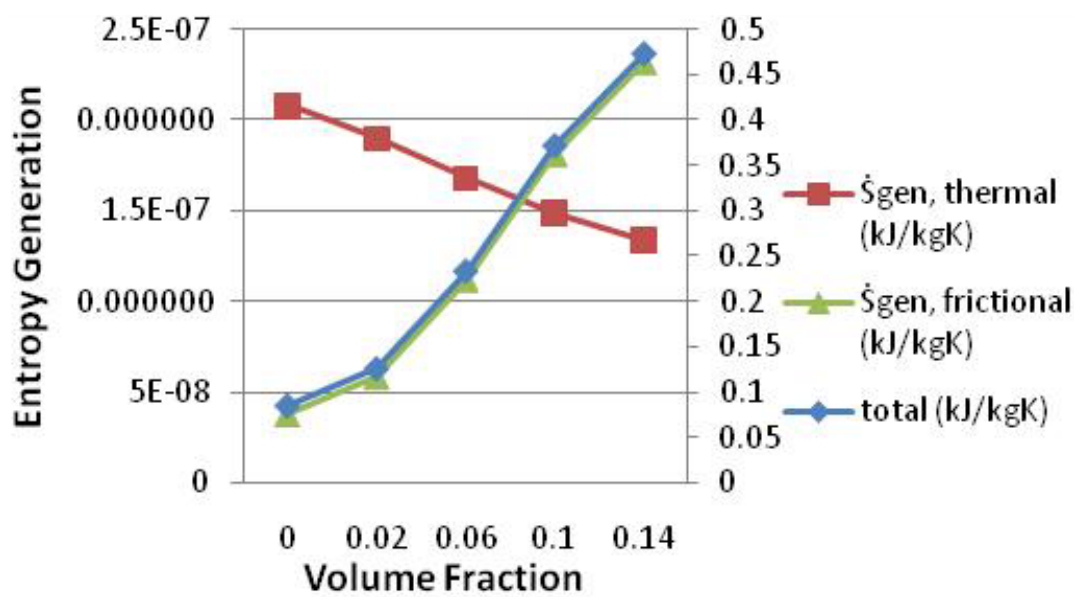

Figure 6 shows the variations of entropy generation from thermal and frictional irreversibility in minichannels. Similar to the trend in microchannels, the thermal irreversibility decreases with an increase of volume fraction, and the frictional irreversibility increases. The drop in the thermal irreversibility, however, is so significant that it overwhelms the effect of the frictional irreversibility increase. As a result, the net entropy generation decreases.

The Bejan number is a dimensionless number defined as the entropy generation ratio of the thermal irreversibility over the total entropy generation [30,31]. That is:

$$
\mathrm{Be}=\frac{\dot{\mathrm{S}}_{\text {gen } \Delta \mathrm{T}}}{\dot{\mathrm{S}}_{\text {gen } \Delta \mathrm{P}}+\dot{\mathrm{S}}_{\text {gen } \Delta \mathrm{T}}}
$$

where:

$\dot{\mathrm{S}}_{\mathrm{gen} \Delta \mathrm{T}}=$ entropy generation due to thermal irreversibility and

$\dot{\mathrm{S}}_{\text {gen } \Delta \mathrm{P}}=$ entropy generation due to frictional irreversibility.

Figure 6. Entropy generation in minichannels.

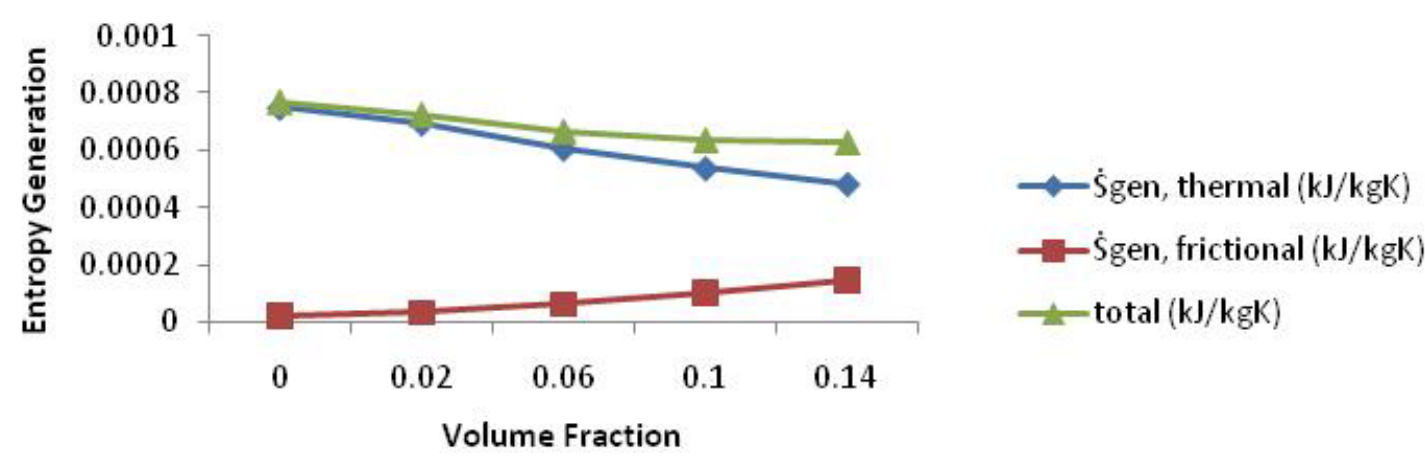

Thus, the Bejan number indicates the fraction of thermal entropy generation compared to the total entropy generation. In another words, this number shows the enhancement in thermal irreversibility for different channels in different flow regimes. Finite temperature difference between the wall of the tube and the fluid generates larger irreversibility for larger channel diameters in comparison to smaller diameters. However for the microchannels, the friction irreversibility becomes overwhelms the entropy generation of the thermal irreversibility and the Bejan number becomes very small. At lower diameters 
for flows in microchannels, while the frictional irreversibility is still significant, and the thermal entropy production is dominant and becomes the main factor in raising the rate of entropy generation; thus, the Bejan $(\mathrm{Be})$ number becomes near 1.

Figures 7 and 8 display the variation of the Bejan numbers $(\mathrm{Be})$ with solid volume fraction in the micro- and minichannels. It is seen that the Be number for both cases follow a decreasing trend with the increase in solid volume fraction. In the microchannel the Be number is very small implying that the generation of thermal irreversibility is negligible compared with the frictional entropy generation. For minichannels, however, $\mathrm{Be}$ is of the order of $0.8-1$, indicating that the thermal effects are the main contributor to the entropy generation.

Figure 7. Bejan number (Be) for microchannels.

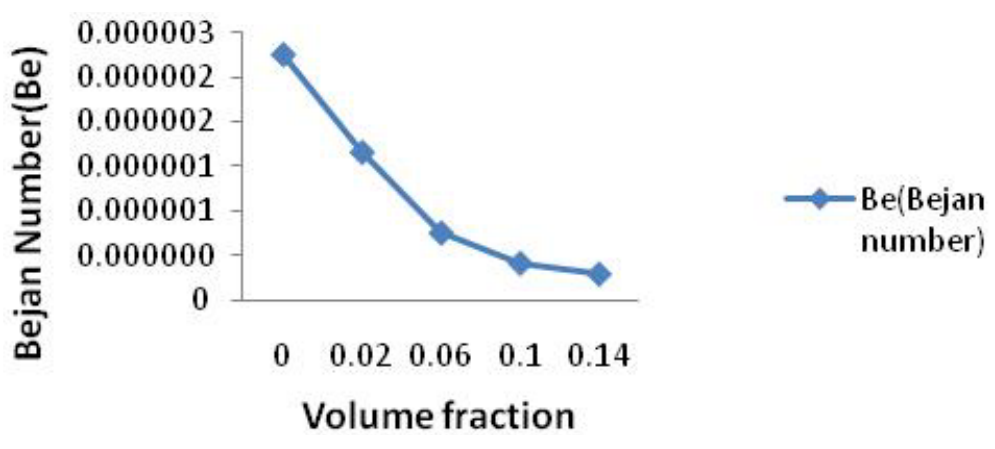

As it can be seen in Figure 5, the variation range of $\dot{S}_{\text {gen } \Delta \mathrm{P}}$ versus the volume fraction is much more than the variation range of $\dot{S}_{\text {gen } \Delta T}$ versus the volume fraction. Therefore, in the expression for the Bejan number, the variation of the denominator is much higher than that of the nominator. This trend is clearly seen in Figure 7. For a volume fraction less than 0.06, the Bejan number variation is affected by $\dot{\mathrm{S}}_{\text {gen } \Delta \mathrm{T}}$ fluctuation. So when the volume fraction is greater than 0.06 , the influence of $\dot{\mathrm{S}}_{\text {gen } \Delta \mathrm{P}}$ becomes more significant and then the cure slope becomes low.

Figure 8. Bejan number (Be) number for minichannels.

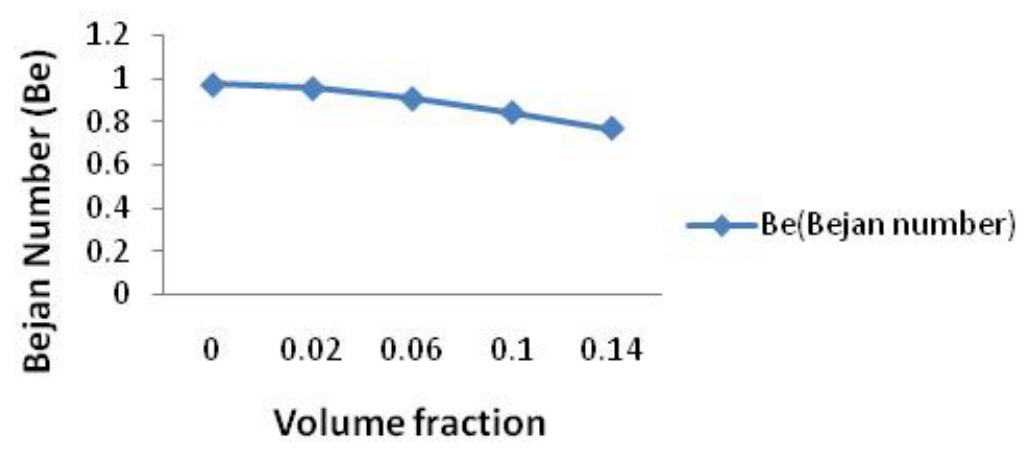

\section{Conclusions}

In this study, the entropy generation in nanofluids was evaluated using two different models for conductivity and viscosity. For alumina-water $\left(\mathrm{Al}_{2} \mathrm{O}_{3}-\mathrm{H}_{2} \mathrm{O}\right)$ nanofluid under laminar flow regime in microchannels, it was observed that the ratio of entropy generation for the nanofluid over the base fluid is higher than unity, and the ratio increases with the increase in solid volume fraction. Therefore, 
the use of the alumina-water nanofluids in microchannels is not recommended. In minichannels, however, the entropy generation rate ratio is less than one and decreases with each increment in solid volume fraction. Therefore, the application of alumina-water nanofluids to a minichannel is advantageous.

\section{Acknowledgments}

This research is supported by the High Impact Research (HIR) grant number D000023-16001-HIR MOHE and UM.C/625/1/HIR/MOHE/ENG/45 University of Malaya.

\section{References}

1. Chopkar, M.; Das, P.K.; Manna, I. Synthesis and characterization of nanofluid for advanced heat transfer applications. Scripta. Mater. 2006, 55, 549-552.

2. Masuda, H.; Ebata, A.; Teramae, K.; Hishinuma, N. Alteration of thermal conductivity and viscosity of liquid by dispersing ultra-fine particles. Netsu. Bussei 1993, 7, 227-233.

3. Choi, S.U.S.; Eastman, J. Enhancing Thermal Conductivity of Fluids with Nanoparticles; Argonne National Lab.: Argonne, Illinois, USA, 1995.

4. Ebrahimnia-Bajestan, E.; Niazmand, H.; Duangthongsuk, W.; Wongwises, S. Numerical investigation of effective parameters in convective heat transfer of nanofluids flowing under a laminar flow regime. Int. J. Heat Mass Trans. 2011, 54, 4376-4388.

5. Abouali, O.; Ahmadi, G. Computer simulations of natural convection of single phase nanofluids in simple enclosures: A critical review. Appl. Therm. Engin. 2011, 36, 1-13.

6. Afshar, H.; Shams, M.; Nainian, S.M.M.; Ahmadi, G. Two-phase study of fluid flow and heat transfer in gas-solid flows (nanofluids). Appl. Mech. Mater. 2012, 110, 3878-3882.

7. Choi, S.; Zhang, Z.; Keblinski, P. Nanofluids, Encyclopedia of Nanoscience and Nanotechnology, Nalwa, H.S. Ed.; American Scientific Publisher: NY, USA, 2004; Volume 5, pp.757-773.

8. Murshed, S.; Leong, K.; Yang, C. Thermophysical and electrokinetic properties of nanofluids-A critical review. Appl. Ther. Engin. 2008, 28, 2109-2125.

9. Singh, P.K.; Anoop, K.; Sundararajan, T.; Das, S.K. Entropy generation due to flow and heat transfer in nanofluids. Inter. J. Heat Mass Trans. 2010, 53, 4757-4767.

10. Prasher, R.; Song, D.; Wang, J.; Phelan, P. Measurements of nanofluid viscosity and its implications for thermal applications. Appl. Phys. Lett. 2006, 89, 133108-133103.

11. Garg, J.; Poudel, B.; Chiesa, M.; Gordon, J.; Ma, J.; Wang, J.; Ren, Z.; Kang, Y.; Ohtani, H.; Nanda, J. Enhanced thermal conductivity and viscosity of copper nanoparticles in ethylene glycol nanofluid. J. Appl. Phys. 2008, 103, 074301-074306.

12. Bejan, A. Second law analysis in heat transfer. Energy 1980, 5, 720-732.

13. Bejan, A. General criterion for rating heat-exchanger performance. Inter. J. Heat Mass Transfer. 1978, 21, 655-658.

14. Cengel, Y.A.; Boles, M.A. Thermodynamics: An Engineering Approach; McGraw-Hill Higher Education: New York, NY, USA, 2006.

15. Carnahan, W.; Ford, K.W.; Prosperetti, A.; Rochlin, G.I.; Rosenfeld, A.H.; Ross, M.H.; Rothberg, J.E.; Seidel, G.M.; Socolow, R.H. Efficient use of energy: A physics perspective. New York: Am. Phys. Society: January. Study Report 1975, 399, 242-773. 
16. Bouabid, M.; Magherbi, M.; Hidouri, N.; Brahim, A.B. Entropy generation at natural convection in an inclined rectangular cavity. Entropy 2011, 13, 1020-1033.

17. Bejan, A. Chapter 5. In Entropy Generation through Heat and Fluid Flow; John Willy and Sons: NY, USA, 1982.

18. Bejan, A.A. Study of entropy generation in fundamental convective heat transfer. J. Heat Trans. 1979, 101, 718-725.

19. Hamilton, R.; Crosser, O. Thermal conductivity of heterogeneous two-component systems. Ind. Engin. Chem. Funda. 1962, 1, 187-191.

20. Einstein, A. Berichtigung zu meiner arbeit:, Eine neue bestimmung der moleküldimensionen. Ann. Phys. 1911, 14, 591-592.

21. Zhang, X.; Gu, H.; Fujii, M. Effective thermal conductivity and thermal diffusivity of nanofluids containing spherical and cylindrical nanoparticles. Exper. Therm. Fluid Sci. 2007, 31, 593-599.

22. Xie, H.; Wang, J.; Xi, T.; Liu, Y.; Ai, F.; Wu, Q. Thermal conductivity enhancement of suspensions containing nanosized alumina particles. J. Appl. Phys. 2002, 91, 4568-4572.

23. Xie, H.; Lee, H.; Youn, W.; Choi, M. Nanofluids containing multiwalled carbon nanotubes and their enhanced thermal conductivities. J. Appl. Phys. 2003, 94, 4967-4971.

24. Eastman, J.A.; Phillpot, S.; Choi, S.; Keblinski, P. Thermal transport in nanofluids 1. Annu. Rev. Mater. Res. 2004, 34, 219-246.

25. Buongiorno, J.; Venerus, D.C.; Prabhat, N.; McKrell, T.; Townsend, J.; Christianson, R.; Tolmachev, Y.V.; Keblinski, P.; Hu, L.; Alvarado, J.L. A benchmark study on the thermal conductivity of nanofluids. J. Appl. Phys. 2009, 106, 094312-094314.

26. Pak, B.C.; Cho, Y.I. Hydrodynamic and heat transfer study of dispersed fluids with submicron metallic oxide particles. Exp. Heat Trans. 1998, 11, 151-170.

27. Maïga, S.E.B.; Palm, S.J.; Nguyen, C.T.; Roy, G.; Galanis, N. Heat transfer enhancement by using nanofluids in forced convection flows. Inter. J. Heat Fluid Flow 2005, 26, 530-546.

28. Anoop, K.; Sundararajan, T.; Das, S.K. Effect of particle size on the convective heat transfer in nanofluid in the developing region. Inter. J. Heat Mass Transfer 2009, 52, 2189-2195.

29. Bergman, T. Effect of reduced specific heats of nanofluids on single phase, laminar internal forced convection. Int. J. Heat Mass Transfer 2009, 52, 1240-1244.

30. Paoletti, S.; Rispoli, F.; Sciubba, E. Calculation of exergetic losses in compact heat exchanger passage. ASME AES 1989, 21-29.

31. Haddad, O.; Abuzaid, M.; Al-Nimr, M. Entropy generation due to laminar incompressible forced convection flow through parallel-plates microchannel. Entropy 2004, 6, 413-426.

(C) 2013 by the authors; licensee MDPI, Basel, Switzerland. This article is an open access article distributed under the terms and conditions of the Creative Commons Attribution license (http://creativecommons.org/licenses/by/3.0/). 